\title{
Intramolecular Cyclization of $\beta, \beta$-Difluorostyrenes Bearing an Iminomethyl or a Diazenyl Group at the Ortho Position: Synthesis of 3- Fluorinated Isoquinoline and Cinnoline Derivatives
}

\author{
Junji Ichikawa, ${ }^{* a}{ }^{a}$ Yukinori Wada, ${ }^{\mathrm{b}}$ Hiroyuki Kuroki, ${ }^{\mathrm{c}}$ Jun Mihara $^{\mathrm{b}}$ and Ryo Nadano ${ }^{\mathrm{b}}$
}

Received (in XXX, XXX) 1st January 2007, Accepted 1st January 2007

First published on the web 1st January 2007

DOI: 10.1039/b000000x

$o$-Formyl-substituted $\beta$, $\beta$-difluorostyrenes readily react with $\mathrm{NH}_{2} \mathrm{OH} \cdot \mathrm{HCl}$ or $\mathrm{NH}_{4} \mathrm{OAc}$ to afford 310 fluoroisoquinoline derivatives in good yield via (i) the formation of the corresponding oximes or imines and (ii) subsequent intramolecular replacement of a vinylic fluorine by the $\mathrm{sp}^{2}$ nitrogen of the iminomethyl group $(\mathrm{HON}=\mathrm{CH}-$ or $\mathrm{HN}=\mathrm{CH}-), \beta, \beta$-Difluorostyrenes bearing an $o$-diazenyl group $(\mathrm{HN}=\mathrm{N}-)$, generated by reduction of the corresponding diazonium ions, undergo a similar substitution to afford 3-fluorinated cinnolines.

\section{${ }_{15}$ Introduction}

Isoquinolines and related derivatives including cinnolines are found in many bioactive natural products. They constitute key structural components in pharmaceuticals, agrochemicals, as well as materials such as dyestuffs and liquid crystals. ${ }^{1,2}$ As a 20 consequence, their synthesis has been a topic of much research over the past years. ${ }^{3,4}$

The introduction of fluorine into the original molecules has come into wide use as one of the most efficient methods for modification of their biological activities as well as their ${ }_{25}$ physical and chemical properties. Thus, fluorine-containing isoquinoline derivatives have attracted considerable attention. ${ }^{5}$ Despite the great utility and immense potential of ring-fluorinated isoquinoline frameworks, both as components and intermediates, ${ }^{6}$ there still remain problems in their 30 synthesis. $\uparrow^{7-9}$

In our recent publications, we have reported the construction of isoquinoline frameworks via the intramolecular substitution of tosylamidate anions, nitrogen nucleophiles bearing an $\mathbf{N}-\mathrm{C}$ single bond $\left(\mathrm{sp}^{3}\right.$-type 35 nucleophiles), for vinylic fluorines in ortho-functionalized $\beta, \beta$-difluorostyrenes 1 (Scheme 1 ). ${ }^{8 \mathrm{a}}$ This ring formation is promoted by the unique reactivity of 1,1-difluoro-1-alkenes toward nucleophilic substitution of their vinylic fluorines via addition-elimination processes,${ }^{5 \mathrm{c}}$ followed by aromatization 40 via elimination of a sulfinic acid to provide the heteroaromatic system 2.

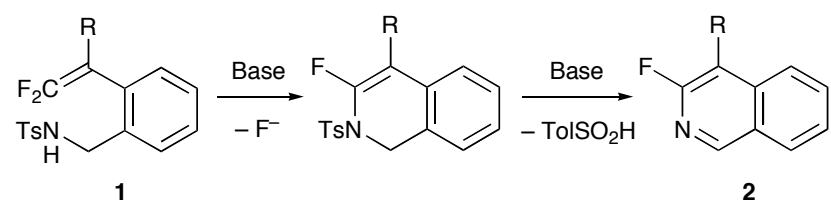

Scheme 1 Construction of isoquinoline nuclei via substitution and elimination

45 On the other hand, nitrogen nucleophiles with an $\mathbf{N}=\mathrm{Y}$ double bond ( $\mathrm{sp}^{2}$ nucleophiles) would give rise to the direct construction of heteroaromatic rings. ${ }^{8 \mathrm{~b}}$ Thus, we investigated a replacement of the vinylic fluorines by nitrogen nucleophiles such as oxime, imine, and diimide nitrogens to so synthesize isoquinoline derivatives. Herein, we wish to report a facile synthesis of 3-fluorinated isoquinolines and their $N$ oxides $^{8}$ or cinnolines ${ }^{9}$ starting from $o$-formyl- or $o$-aminosubstituted $\beta, \beta$-difluorostyrenes, respectively.

\section{Results and discussion}

${ }_{55}$ Synthesis of 3-fluoroisoquinoline $\mathrm{N}$-oxides and 3fluoroisoquinolines

For the purpose of preparing the starting $\beta, \beta$-difluorostyrenes 4 with an oxime moiety at the ortho position, $\beta, \beta$-difluoro-oformylstyrenes $\mathbf{3}$ were treated with hydroxyamine 60 hydrochloride $\left(\mathrm{NH}_{2} \mathrm{OH} \cdot \mathrm{HCl}\right)$ in the presence of $\mathrm{Et}_{3} \mathrm{~N}$. Unexpectedly, the reaction directly produced 3fluoroquinoline $N$-oxide $\mathbf{5 a}$ in $67 \%$ yield, instead of the expected oxime 4a (Scheme 2 ). This result suggests that $\beta, \beta$ difluoro-o-formylstyrene $\mathbf{3 a}$ was initially converted into ${ }_{65}$ oxime $4 \mathbf{a}$, which in turn readily underwent the intramolecular vinylic substitution, followed by deprotonation on the oxygen, leading to the final product, isoquinoline $\mathrm{N}$-oxide $\mathbf{5 a}+$

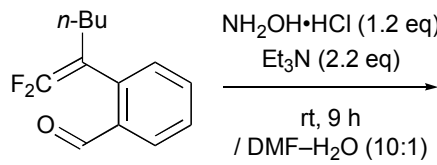

3a

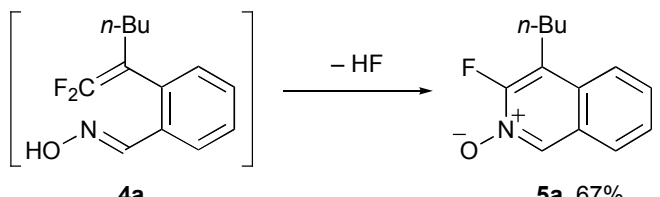

Scheme 2 Construction of isoquinoline nuclei via substitution from 4

70 Although this cyclization successfully proceeded, there was 
a drawback in the thermal instability of the starting material, $\beta, \beta$-difluoro-o-formylstyrenes 3 . The coupling reaction of an in-situ generated 2,2-difluorovinylborane with $o$ iodobenzaldhyde ${ }^{10}$ afforded $3 \mathbf{a}$ in $84 \%$ yield, as determined by

${ }_{5}^{19} \mathrm{~F}$ NMR, while the isolated yield was reduced to $62 \%$ after silica gel column chromatography. Then, we tried to combine the coupling reaction and the cyclization without purification of unstable $\mathbf{3}$, which process could improve the synthesis of $\mathbf{5}$. After the generation of difluorovinylboranes from 2,2,2-

10 trifluoroethyl 4-methylbenzenesulfonate $\left(\mathrm{CF}_{3} \mathrm{CH}_{2} \mathrm{OTs}\right)$ and their coupling reaction with $o$-iodobenzaldehyde, the crude products were treated with $\mathrm{NH}_{2} \mathrm{OH} \cdot \mathrm{HCl}$, leading to the isoquinoline $N$-oxides $\mathbf{5 a}$ and $\mathbf{5 b}(\mathrm{R}=n$ - $\mathrm{Bu}$ and $s e c-\mathrm{Bu})$ in $71 \%$ and $69 \%$ yields from the starting $o$-iodobenzaldehyde 15 (Scheme 3).

As further examples of this type of cyclization, we examined a similar in-situ preparation of imine nitrogen nucleophiles $(\mathrm{HN}=\mathrm{CH}-)$. When the crude formylstyrenes 3 were treated with $\mathrm{NH}_{4} \mathrm{OAc}$ as an ammonia source, 20 dehydration and subsequent cyclization were smoothly induced to give isoquinolines $\mathbf{6 a}$ and $\mathbf{6 b}(\mathrm{R}=n$ - $\mathrm{Bu}$ and $s e c$ $\mathrm{Bu}$ ) in $70 \%$ and $71 \%$ yields based on $o$-iodobenzaldhyde, respectively (Scheme 3$)$.

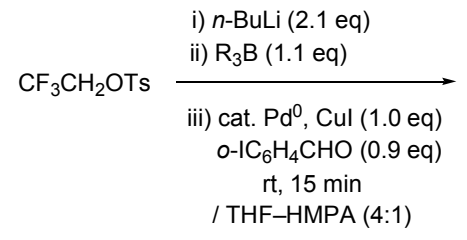

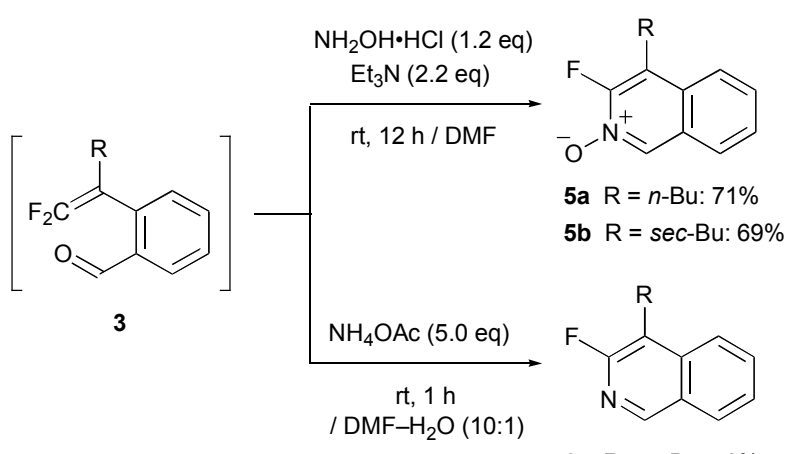

6a $\mathrm{R}=n$-Bu: $70 \%$

6b $\mathrm{R}=\sec -\mathrm{Bu}: 71 \%$

$25 \quad$ Scheme 3 Synthesis of 3-fluoroisoquinoline $N$-oxides 5 and 3fluoroisoquinolines 6

\section{Reactions of 3-fluoroisoquinoline N-oxides}

The remaining fluorines in isoquinoline $N$-oxides $\mathbf{5}$ were expected to be quite reactive toward replacement by 30 nucleophiles via similar addition-elimination processes, which allows the introduction of another substituent into the isoquinoline nuclei. Initially, we attempted the reaction of $\mathbf{5 a}$ with oxygen and sulfur nucleophiles. On treatment of 5a with $\mathrm{KO} t$ - $\mathrm{Bu}$ or $\mathrm{LiSPh}$ as a nucleophile in THF, the expected 35 substitution of the fluorine proceeded to give the corresponding insoquinoline $N$-oxide $7 \mathbf{a}$ or $\mathbf{7 b}$ bearing an oxygen or a sulfur functional group at the 3-position (Scheme 4; Table 1, entries 1 and 2). A nitrogen nucleophile, pyrrolidine, also brought about a similar substitution under 40 less basic conditions to yield $\mathbf{7 c}$ (Table 1 , entry 3 ). Thus, the reaction of 5a with nucleophiles occurred regioselectively at the 3-position via ipso-attack, whereas it is known that isoquinolines are highly reactive toward nucleophiles at their 1 -position. ${ }^{8 \mathrm{e}}$

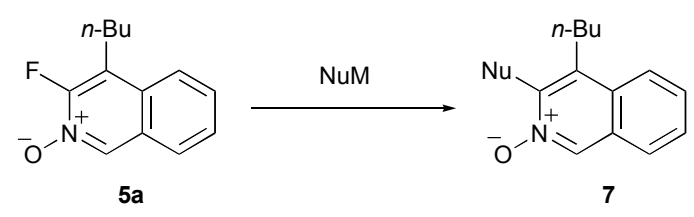

Scheme 4 Introduction of substituent at the 3-position of $\mathbf{5 a}$ via substitution

Table 1 Introduction of Substituent at the 3-Position of 5a

\begin{tabular}{ccccc} 
Entry & NuM (eq) & Solvent & Conditions & Yield $/ \%(7)$ \\
\hline 1 & $t$-BuOK (1.5) & THF & $-78{ }^{\circ} \mathrm{C}, 0.5 \mathrm{~h}$ & $72(\mathbf{7 a})$ \\
2 & $\operatorname{PhSLi}(1.5)$ & $\mathrm{THF}$ & $-78{ }^{\circ} \mathrm{C}$ to $0{ }^{\circ} \mathrm{C}, 5 \mathrm{~h}$ & $85(\mathbf{7 b})$ \\
3 & pyrrolidine (4.1) & Toluene & reflux, $23 \mathrm{~h}$ & $74(7 \mathbf{c})$ \\
\hline
\end{tabular}

50 In addition, the cycloaddition of 5a was attempted by employing phenylisocyanate (PhNCO) as a dipolarophile, because isoquinoline $N$-oxides are well known to act as 1,3dipoles. On treatment of 5a with PhNCO in DMF, the expected reaction proceeded with accompanying ${ }_{55}$ decarboxylation to give 1-anilino-3-fluoroisoquinoline 8a. In contrast to the above-mentioned introduction of a substituent at the 3-position, the amino group was exclusively introduced at the 1-position (Scheme 5). $\|^{11}$ Thus, these sequences of processes provide a versatile method for the synthesis of 3,4${ }_{60}$ disubstituted and 1,3,4-trisubstituted isoquinoline derivatives starting from $\mathrm{CF}_{3} \mathrm{CH}_{2} \mathrm{OTs}$ and $o$-iodobenzaldehyde.

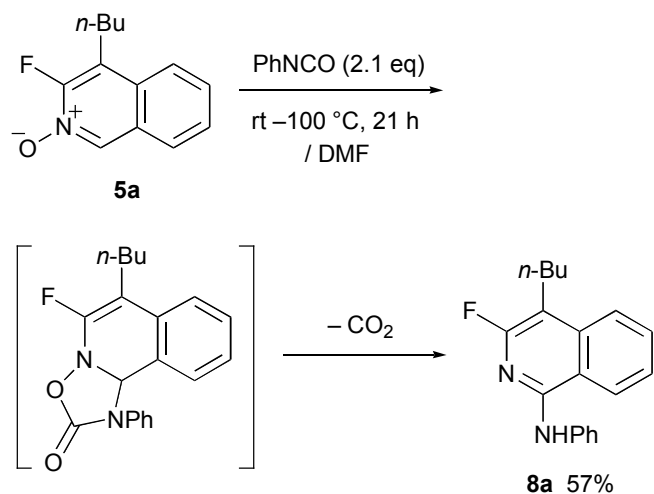

Scheme 5 Introduction of substituent at the 1-position of 5a via 1,3dipolar addition

\section{${ }_{65}$ Synthesis of 3-fluorocinnolines}

As shown in Scheme 3, the direct construction of isoquinoline nuclei has been successfully achieved by the intramolecular substitution of the oxime and imine $\mathrm{sp}^{2}$ nitrogen $(\mathrm{HON}=\mathrm{CH}-$ and $\mathrm{HN}=\mathrm{CH}-$ ). Using this tactics, we next investigated the 70 intramolecular substitution of a diimide $\mathrm{sp}^{2}$ nitrogen $(\mathrm{HN}=\mathrm{N}-)$, where the imino carbon was replaced by a nitrogen atom. This reaction would result in the construction of the cinnoline ring structure. 
$o$-Amino- $\beta, \beta$-difluorostyrenes $\quad \mathbf{9}, \quad$ prepared from $\mathrm{CF}_{3} \mathrm{CH}_{2} \mathrm{OTs}$ and $o$-iodoaniline, ${ }^{12}$ were treated with isoamyl nitrite ( $i$-AmONO) for diazotization, and then subsequently reduced with $n-\mathrm{Bu}_{3} \mathrm{SnH}$. The expected intramolecular substitution of the terminal diazenyl nitrogen $(\mathrm{HN}=\mathrm{N}-)$ proceeded smoothly, to give 3-fluorocinnoline 10a in $58 \%$ yield.: Then we tried several other reducing reagents, and found that benzenethiol raised the yield of 10a and $10 \mathrm{~b}(\mathrm{R}=$ $n$ - $\mathrm{Bu}$ and $s e c-\mathrm{Bu}$ ) to $88 \%$ and $87 \%$, respectively (Scheme 6 ).

10 In the reaction of 9a, diphenyl disulfide ( $\mathrm{PhSSPh}$ ) was obtained in $90 \%$ yield based on $\mathrm{PhSH}$, which implies that $\mathrm{PhSH}$ definitely acted as a reducing agent.<smiles>[R]C(=C=[C-])c1ccccc1N</smiles>

$\mathrm{CF}_{3} \mathrm{CO}_{2} \mathrm{H}(2.0 \mathrm{eq})$

i-AmONO

$0{ }^{\circ} \mathrm{C}, 0.5 \mathrm{~h}$

$/ \mathrm{CH}_{3} \mathrm{CN}$

9a $\mathrm{R}=n-\mathrm{Bu}$

9b $\mathrm{R}=\sec -\mathrm{Bu}$

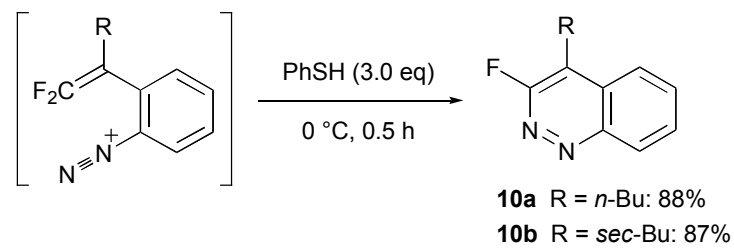

Scheme 6 Synthesis of 3-fluoroccinnolines 10

\section{${ }_{15}$ Conclusion}

We have accomplished the construction of isoquinoline and cinnoline frameworks via intramolecular cyclization of $\beta, \beta$ difluorostyrenes bearing a hydroxyiminomethyl $(\mathrm{HON}=\mathrm{CH}-)$, an iminomethyl $(\mathrm{HN}=\mathrm{CH}-)$ or a diazenyl $(\mathrm{HN}=\mathrm{N}-)$ group at 20 the ortho position. The $\beta, \beta$-difluorostyrenes, prepared from $\mathrm{CF}_{3} \mathrm{CH}_{2} \mathrm{OTs}$, trialkylboranes and $o$-formyl- or $o$-aminosubstituted aryl iodides, readily undergo six-membered ring closure via dehydration or diazotization under mild conditions compatible with a variety of functional groups. Thus, this 25 sequence provides a facile method for the synthesis of selectively ring-fluorinated nitrogen heterocycles.

\section{Experimental}

${ }^{1} \mathrm{H}$ NMR, ${ }^{13} \mathrm{C}$ NMR, and ${ }^{19} \mathrm{~F}$ NMR spectra were recorded on a 30 JEOL JNM-A-500 or a Bruker DRX 500 spectrometer. ${ }^{1} \mathrm{H}$ NMR chemical shifts $\left(\delta_{\mathrm{H}}\right)$ are given in ppm downfield from $\mathrm{Me}_{4}$ Si. ${ }^{13} \mathrm{C}$ NMR chemical shifts $\left(\delta_{\mathrm{C}}\right)$ are given in ppm downfield from $\mathrm{Me}_{4} \mathrm{Si}$, relative to chloroform- $d(\delta=77.0)$. ${ }^{19} \mathrm{~F}$ NMR chemical shifts $\left(\delta_{\mathrm{F}}\right)$ are given in ppm downfield ${ }_{35}$ from $\mathrm{C}_{6} \mathrm{~F}_{6}$. IR spectra were recorded on a Shimadzu IR-408 spectrometer or a JEOL JIR-WINSPEC50 spectrometer. Elemental analyses were performed with a YANAKO MT-6 CHN Corder apparatus. Mass spectra were taken with a JEOL MS-700M spectrometer.

${ }_{40}$ All reactions were carried out under nitrogen. Tetrahydrofuran (THF) was distilled from sodium benzophenone ketyl prior to use. $N, N$-Dimethylformamide (DMF) was distilled under reduced pressure from $\mathrm{CaH}_{2}$ and stored over molecular sieves $4 \AA$. Acetonitrile $\left(\mathrm{CH}_{3} \mathrm{CN}\right)$ was distilled under reduced 45 pressure from $\mathrm{CaH}_{2}$ and stored over molecular sieves $3 \AA$. Hexamethylphosphoric triamide (HMPA) was distilled under reduced pressure from $\mathrm{CaH}_{2}$ and stored over molecular sieves $4 \AA$. Toluene was distilled and stored over sodium. Column chromatography and preparative thin-layer chromatography so were performed on silica gel (Kanto Chemical Co. Inc., Silica Gel 60 and Wako Pure Chemical Industries, Ltd., B5-F), respectively.

\section{Synthesis of 3-fluoroisoquinoline $\mathrm{N}$-oxides and 3- ${ }_{55}$ fluoroisoquinolines}

\section{o-(1,1-Difluorohex-1-en-2-yl)benzald ehyde (3a)}

Butyllithium (5.0 mL, 1.7 M in hexane, $8.4 \mathrm{mmol}$ ) was added to a solution of $\mathrm{CF}_{3} \mathrm{CH}_{2} \mathrm{OTs}(1.0 \mathrm{~g}, 4.0 \mathrm{mmol})$ in THF (20 $\mathrm{mL})$ at $-78{ }^{\circ} \mathrm{C}$ over $10 \mathrm{~min}$. The reaction mixture was stirred 60 for $20 \mathrm{~min}$ at $-78{ }^{\circ} \mathrm{C}$, and then tributylborane $(4.4 \mathrm{~mL}, 1.0 \mathrm{M}$ in THF, $4.4 \mathrm{mmol}$ ) was added at $-78^{\circ} \mathrm{C}$. After being stirred for $1 \mathrm{~h}$, the reaction mixture was allowed to warm up to room temperature and stirred for an additional $3 \mathrm{~h}$. The solution was treated with HMPA $(5.0 \mathrm{~mL})$, triphenylphosphine $(30 \mathrm{mg}$, $\left.{ }_{65} 0.11 \mathrm{mmol}\right)$, and tris(dibenzylideneacetone)dipalladiumchloroform (1/1) $(29 \mathrm{mg}, 0.028 \mathrm{mmol})$ and stirred for $15 \mathrm{~min}$. To the resulting solution were added $o$-iodobenzaldehyde (738 $\mathrm{mg}, 3.2 \mathrm{mmol})$ and copper(I) iodide $(757 \mathrm{mg}, 4.0 \mathrm{mmol})$. After the mixture was stirred for $20 \mathrm{~min}$ at room temperature, 70 the reaction was quenched with phosphate buffer $(\mathrm{pH} 7)$. The mixture was filtered through a Celite pad, and then organic materials were extracted with AcOEt three times. The combined extracts were washed with brine and dried over $\mathrm{Na}_{2} \mathrm{SO}_{4}$. After removal of the solvent under reduced pressure, 75 the residue was purified by column chromatography on silica gel $\left(\mathrm{Et}_{2} \mathrm{O}\right.$-hexane $\left.1: 20\right)$ to give 3a $(441 \mathrm{mg}, 62 \%)$ as a pale yellow liquid. ${ }^{1} \mathrm{H} \mathrm{NMR}\left(500 \mathrm{MHz}, \mathrm{CDCl}_{3}\right) \delta_{\mathrm{H}} 0.86(3 \mathrm{H}, \mathrm{t}, J=$ $7.2 \mathrm{~Hz}), 1.29-1.35(4 \mathrm{H}, \mathrm{m}), 2.37-2.43(2 \mathrm{H}, \mathrm{m}), 7.31(1 \mathrm{H}, \mathrm{dd}$, $J=7.6,0.6 \mathrm{~Hz}), 7.47(1 \mathrm{H}, \mathrm{dd}, J=7.6,7.6 \mathrm{~Hz}), 7.61(1 \mathrm{H}, \mathrm{ddd}$, $\left.{ }_{80} J=7.6,7.6,1.5 \mathrm{~Hz}\right), 7.96(1 \mathrm{H}, \mathrm{dd}, J=7.6,1.5 \mathrm{~Hz}), 10.16(1 \mathrm{H}$, $\mathrm{d}, J=1.5 \mathrm{~Hz}) \cdot{ }^{13} \mathrm{C} \mathrm{NMR}\left(126 \mathrm{MHz}, \mathrm{CDCl}_{3}\right) \delta_{\mathrm{C}} 13.6,22.2$, $29.5\left(\mathrm{~d}, J_{\mathrm{CF}}=3 \mathrm{~Hz}\right), 29.5,89.1\left(\mathrm{dd}, J_{\mathrm{CF}}=24,17 \mathrm{~Hz}\right), 128.3$, $128.6,130.6\left(\mathrm{~d}, J_{\mathrm{CF}}=2 \mathrm{~Hz}\right), 133.9,134.1,137.3\left(\mathrm{~d}, J_{\mathrm{CF}}=4\right.$ $\mathrm{Hz}), 152.7\left(\mathrm{dd}, J_{\mathrm{CF}}=290,287 \mathrm{~Hz}\right), 191.1 .{ }^{19} \mathrm{~F}$ NMR $(470$ $\left.{ }_{85} \mathrm{MHz}_{\mathrm{CDCl}}\right) \delta_{\mathrm{F}} 70.0\left(1 \mathrm{~F}, \mathrm{dt}, J_{\mathrm{FF}}=43 \mathrm{~Hz}, J_{\mathrm{FH}}=3 \mathrm{~Hz}\right), 72.8$ $\left(1 \mathrm{~F}, \mathrm{dd}, J_{\mathrm{FF}}=43 \mathrm{~Hz}, J_{\mathrm{FH}}=2 \mathrm{~Hz}\right.$ ). IR (neat) 2970, 2950, 2890, $1840,1745,1705,1600,1470,1465,1245 \mathrm{~cm}^{-1}$. MS (EI, 70 eV) $m / z 224\left(\mathrm{M}^{+}, 20 \%\right), 205$ (44), 131 (100), 91 (44). HRMS $\mathrm{m} / z$ calcd for $\mathrm{C}_{13} \mathrm{H}_{14} \mathrm{~F}_{2} \mathrm{O} 224.1013\left(\mathrm{M}^{+}\right)$; found 224.1000 .

\section{4-Butyl-3-fluoroisoquinoline $\mathrm{N}$-oxide (5a)}

Butyllithium (1.1 mL, 1.49 $\mathrm{M}$ in hexane, $1.7 \mathrm{mmol})$ was added to a THF (4.5 mL) solution of $\mathrm{CF}_{3} \mathrm{CH}_{2} \mathrm{OTs}(203 \mathrm{mg}$, $0.80 \mathrm{mmol})$ at $-78{ }^{\circ} \mathrm{C}$ over $10 \mathrm{~min}$. The reaction mixture was 95 stirred for $20 \mathrm{~min}$ at $-78^{\circ} \mathrm{C}$, and then tributylborane $(0.88 \mathrm{~mL}$, $1.0 \mathrm{M}$ in THF, $0.88 \mathrm{mmol}$ ) was added at $-78{ }^{\circ} \mathrm{C}$. After being stirred for $1 \mathrm{~h}$, the reaction mixture was allowed to warm up to room temperature and stirred for an additional $3 \mathrm{~h}$. The solution was treated with HMPA (1.5 $\mathrm{mL})$, 100 triphenylphosphine $(17 \quad \mathrm{mg}, \quad 0.065 \quad \mathrm{mmol})$ and 
tris(dibenzylideneacetone)dipalladium-chloroform (1/1) (25 $\mathrm{mg}, 0.024 \mathrm{mmol})$ and stirred for $15 \mathrm{~min}$. To the resulting solution was added $o$-iodobenzaldehyde $(167 \mathrm{mg}, 0.72 \mathrm{mmol})$ and copper(I) iodide $(153 \mathrm{mg}, 0.80 \mathrm{mmol})$. After the mixture 5 was stirred for $15 \mathrm{~min}$ at room temperature, the reaction was quenched with phosphate buffer $(\mathrm{pH} 7)$. The mixture was filtered through a Celite pad, and then organic materials were extracted with $\mathrm{Et}_{2} \mathrm{O}$ three times. The combined extracts were washed with brine and dried over $\mathrm{Na}_{2} \mathrm{SO}_{4}$. After removal of 10 the solvent under reduced pressure, the residue, crude aldehyde 3a, was dissolved in DMF $(3.0 \mathrm{~mL})$. The resulting mixture was treated with $\mathrm{NH}_{2} \mathrm{OH} \cdot \mathrm{HCl}(160 \mathrm{mg}, 0.96 \mathrm{mmol})$ and $\mathrm{Et}_{3} \mathrm{~N}(0.22 \mathrm{~mL}, 1.8 \mathrm{mmol})$ and stirred for $12 \mathrm{~h}$. The reaction was quenched with phosphate buffer $(\mathrm{pH} 7)$, and 15 organic materials were extracted with $\mathrm{CHCl}_{3}$ three times. After removal of the solvent under reduced pressure, the residue was purified by thin layer chromatography on silica gel (MeOH-AcOEt 1:20) to give 5a $(112 \mathrm{mg}, 71 \%)$ as a pale yellow liquid. ${ }^{1} \mathrm{H}$ NMR $\left(500 \mathrm{MHz}, \mathrm{CDCl}_{3}\right) \delta_{\mathrm{H}} 0.98(3 \mathrm{H}, \mathrm{t}, J=$ $207.5 \mathrm{~Hz}), 1.47(2 \mathrm{H}, \mathrm{tq}, J=7.5,7.5 \mathrm{~Hz}), 1.69(2 \mathrm{H}, \mathrm{tt}, J=7.5$, $7.5 \mathrm{~Hz}), 3.06\left(2 \mathrm{H}, \mathrm{dt}, J=7.5 \mathrm{~Hz}, J_{\mathrm{HF}}=2.0 \mathrm{~Hz}\right), 7.59(1 \mathrm{H}, \mathrm{t}, J$ $=7.8 \mathrm{~Hz}), 7.66(1 \mathrm{H}, \mathrm{t}, J=7.8 \mathrm{~Hz}), 7.74(1 \mathrm{H}, \mathrm{d}, J=7.8 \mathrm{~Hz})$, $7.90(1 \mathrm{H}, \mathrm{d}, J=7.8 \mathrm{~Hz}), 8.75\left(1 \mathrm{H}, \mathrm{d}, J_{\mathrm{HF}}=6.4 \mathrm{~Hz}\right) .{ }^{13} \mathrm{C} \mathrm{NMR}$ $\left(126 \mathrm{MHz}, \mathrm{CDCl}_{3}\right) \delta_{\mathrm{C}} 13.8,22.6,24.3,31.5,119.0\left(\mathrm{~d}, J_{\mathrm{CF}}=\right.$ $2517 \mathrm{~Hz}), 123.2\left(\mathrm{~d}, J_{\mathrm{CF}}=6 \mathrm{~Hz}\right), 125.6\left(\mathrm{~d}, J_{\mathrm{CF}}=2 \mathrm{~Hz}\right), 126.1(\mathrm{~d}$, $\left.J_{\mathrm{CF}}=3 \mathrm{~Hz}\right), 128.2,128.2,129.5,135.6\left(\mathrm{~d}, J_{\mathrm{CF}}=7 \mathrm{~Hz}\right), 153.5$ $\left(\mathrm{d}, J_{\mathrm{CF}}=252 \mathrm{~Hz}\right) .{ }^{19} \mathrm{~F} \mathrm{NMR}\left(470 \mathrm{MHz}, \mathrm{CDCl}_{3}\right) \delta_{\mathrm{F}} 46.7\left(\mathrm{~d}, J_{\mathrm{FH}}\right.$ $=6 \mathrm{~Hz}) . \mathrm{IR}(\mathrm{KBr}$ disk) 1630, 1605, 1500, 1485, 1440, 1390, $1325,1240,1190,1120 \mathrm{~cm}^{-1}$. MS (EI, $\left.70 \mathrm{eV}\right) \mathrm{m} / \mathrm{z} 219\left(\mathrm{M}^{+}\right.$, $30100 \%), 160$ (72), 149 (47), 101 (17). Anal. Found: C, 71.15; $\mathrm{H}, 6.43 ; \mathrm{N}, 6.24$. Calcd for $\mathrm{C}_{13} \mathrm{H}_{14} \mathrm{FNO}$ : C, 71.21; H, 6.44; N, $6.39 \%$.

4-(Butan-2-yl)-3-fluoroisoqunoline $\boldsymbol{N}$-oxide (5b)

${ }_{35}$ Compound 5b was prepared by the method described for $\mathbf{5 a}$ using butyllithium (1.1 mL, $1.49 \mathrm{M}$ in hexane, $1.7 \mathrm{mmol})$, $\mathrm{CF}_{3} \mathrm{CH}_{2} \mathrm{OTs}$ (203 mg, $\left.0.80 \mathrm{mmol}\right)$, tri(butan-2-yl)borane $(0.88$ $\mathrm{mL}, \quad 1.0 \mathrm{M}$ in THF, $0.88 \mathrm{mmol})$, HMPA $(1.5 \mathrm{~mL})$, triphenylphosphine $\quad(17 \quad \mathrm{mg}, \quad 0.065 \quad \mathrm{mmol})$, 40 tris(dibenzylideneacetone)dipalladium-chloroform (1/1) (25 $\mathrm{mg}, 0.024 \mathrm{mmol})$, $o$-iodobenzaldehyde $(167 \mathrm{mg}, 0.72 \mathrm{mmol})$ and copper(I) iodide $(153 \mathrm{mg}, 0.80 \mathrm{mmol})$ in THF $(4.5 \mathrm{~mL})$. Then, crude aldehyde $\mathbf{3 b}$ was treated with $\mathrm{NH}_{2} \mathrm{OH} \cdot \mathrm{HCl}(160$ $\mathrm{mg}, 0.96 \mathrm{mmol})$ and $\mathrm{Et}_{3} \mathrm{~N}(0.22 \mathrm{~mL}, 1.8 \mathrm{mmol})$ in DMF $(3.0$ ${ }_{45} \mathrm{~mL}$ ). Purification by thin layer chromatography on silica gel (MeOH-AcOEt 1:20) to give $\mathbf{5 b}(109 \mathrm{mg}, 69 \%)$ as a pale yellow liquid. ${ }^{1} \mathrm{H}$ NMR $\left(500 \mathrm{MHz}, \mathrm{CDCl}_{3}\right) \delta_{\mathrm{H}} 0.90(3 \mathrm{H}, \mathrm{t}, J=$ $7.2 \mathrm{~Hz}), 1.48\left(3 \mathrm{H}, \mathrm{dd}, J=7.2 \mathrm{~Hz}, J_{\mathrm{HF}}=1.4 \mathrm{~Hz}\right), 1.84-2.04$ $(2 \mathrm{H}, \mathrm{m}), 3.50(1 \mathrm{H}, \mathrm{tq}, J=7.2,7.2 \mathrm{~Hz}), 7.58(1 \mathrm{H}, \mathrm{dd}, J=7.8$, $\left.{ }_{50} 7.8 \mathrm{~Hz}\right), 7.65(1 \mathrm{H}, \mathrm{dd}, J=7.8,7.8 \mathrm{~Hz}), 7.74(1 \mathrm{H}, \mathrm{d}, J=7.8$ $\mathrm{Hz}), 8.05(1 \mathrm{H}, \mathrm{d}, J=7.8 \mathrm{~Hz}), 8.77\left(1 \mathrm{H}, \mathrm{d}, J_{\mathrm{HF}}=6.4 \mathrm{~Hz}\right) .{ }^{13} \mathrm{C}$ $\operatorname{NMR}\left(126 \mathrm{MHz}, \mathrm{CDCl}_{3}\right) \delta_{\mathrm{C}} 12.7,18.9\left(\mathrm{~d}, J_{\mathrm{CF}}=4 \mathrm{~Hz}\right), 28.2(\mathrm{~d}$, $\left.J_{\mathrm{CF}}=3 \mathrm{~Hz}\right), 33.6,123.2\left(\mathrm{~d}, J_{\mathrm{CF}}=15 \mathrm{~Hz}\right), 123.3\left(\mathrm{~d}, J_{\mathrm{CF}}=4\right.$ $\mathrm{Hz}), 125.8\left(\mathrm{~d}, J_{\mathrm{CF}}=2 \mathrm{~Hz}\right), 126.2\left(\mathrm{~d}, J_{\mathrm{CF}}=3 \mathrm{~Hz}\right), 128.0\left(\mathrm{~d}, J_{\mathrm{CF}}\right.$ $\left.{ }_{55}=3 \mathrm{~Hz}\right), 129.5,129.6\left(\mathrm{~d}, J_{\mathrm{CF}}=8 \mathrm{~Hz}\right), 135.7\left(\mathrm{~d}, J_{\mathrm{CF}}=8 \mathrm{~Hz}\right)$, $153.9\left(\mathrm{~d}, J_{\mathrm{CF}}=256 \mathrm{~Hz}\right) .{ }^{19} \mathrm{~F}$ NMR $\left(470 \mathrm{MHz} \mathrm{CDCl}_{3}\right) \delta_{\mathrm{F}} 50.9$ (br s). IR (KBr disk) 2960, 2940, 2870, 1480, 1435, 1315, $1230,1215,1190,1120,920 \mathrm{~cm}^{-1}$. MS (EI, $\left.70 \mathrm{eV}\right) \mathrm{m} / \mathrm{z} 219$
$\left(\mathrm{M}^{+}, 100 \%\right), 174$ (50), 115 (47). HRMS $\mathrm{m} / \mathrm{z}$ calcd for ${ }_{60} \mathrm{C}_{13} \mathrm{H}_{14} \mathrm{FNO} 219.1059\left(\mathrm{M}^{+}\right)$; found 219.1082.

\section{4-Butyl-3-fluoroisoquinoline (6a)}

Butyllithium $(0.65 \mathrm{~mL}, 1.62 \mathrm{M}$ in hexane, $1.05 \mathrm{mmol})$ was added to a THF $(2.5 \mathrm{~mL})$ solution of $\mathrm{CF}_{3} \mathrm{CH}_{2} \mathrm{OTs}(127 \mathrm{mg}$, $\left.{ }_{65} 0.50 \mathrm{mmol}\right)$ at $-78{ }^{\circ} \mathrm{C}$ over $10 \mathrm{~min}$. The reaction mixture was stirred for $20 \mathrm{~min}$ at $-78^{\circ} \mathrm{C}$, and then tributylborane $(0.55 \mathrm{~mL}$, $1.0 \mathrm{M}$ in THF, $0.55 \mathrm{mmol}$ ) was added at $-78^{\circ} \mathrm{C}$. After being stirred for $1 \mathrm{~h}$, the reaction mixture was allowed to warm up to room temperature and stirred for an additional $3 \mathrm{~h}$. The 70 solution was treated with HMPA $(0.63 \mathrm{~mL})$, triphenylphosphine $\quad(11 \mathrm{mg}, \quad 0.040 \quad \mathrm{mmol}), \quad$ and tris(dibenzylideneacetone)dipalladium-chloroform (1/1) (10 $\mathrm{mg}, 0.010 \mathrm{mmol}$ ) and stirred for $15 \mathrm{~min}$. To the resulting solution were added $o$-iodobenzaldehyde (104 mg, 0.45 $75 \mathrm{mmol})$ and copper(I) iodide $(95 \mathrm{mg}, 0.50 \mathrm{mmol})$. After the mixture had been stirred for $20 \mathrm{~min}$ at room temperature, the reaction was quenched with phosphate buffer $(\mathrm{pH} 7)$. The mixture was filtered through a Celite pad, and then organic materials were extracted with $\mathrm{Et}_{2} \mathrm{O}$ three times. The combined 80 extracts were washed with water and brine, and then dried over $\mathrm{MgSO}_{4}$. After removal of the solvent under reduced pressure, the residue was dissolved in DMF $(4.5 \mathrm{~mL})$. The resulting mixture was treated with $\mathrm{H}_{2} \mathrm{O}(0.45 \mathrm{~mL})$ and $\mathrm{NH}_{4} \mathrm{OAc}(173 \mathrm{mg}, 2.2 \mathrm{mmol})$ and then stirred for $1 \mathrm{~h}$ at room 85 temperature. The reaction mixture was diluted with $\mathrm{H}_{2} \mathrm{O}$, and organic materials were extracted with AcOEt three times. The combined extracts were washed with water and brine, and then dried over $\mathrm{Na}_{2} \mathrm{SO}_{4}$. After removal of the solvent under reduced pressure, the residue was purified by thin layer 90 chromatography on silica gel (AcOEt-hexane 1:10, and then benzene-hexane $2: 1)$ to give 6 a $(64 \mathrm{mg}, 70 \%) .{ }^{1} \mathrm{H}$ NMR $(500$ $\left.\mathrm{MHz}, \mathrm{CDCl}_{3}\right) \delta_{\mathrm{H}} 0.97(3 \mathrm{H}, \mathrm{t}, J=7.5 \mathrm{~Hz}), 1.46(2 \mathrm{H}, \mathrm{tq}, J=7.5$, $7.5 \mathrm{~Hz}), 1.63-1.71(2 \mathrm{H}, \mathrm{m}), 3.03\left(2 \mathrm{H}, \mathrm{dt}, J=7.5 \mathrm{~Hz}, J_{\mathrm{HF}}=0.9\right.$ $\mathrm{Hz}), 7.52\left(1 \mathrm{H}, \mathrm{ddd}, J=8.0,8.0 \mathrm{~Hz}, J_{\mathrm{HF}}=0.8 \mathrm{~Hz}\right), 7.71(1 \mathrm{H}$, $95 \mathrm{dd}, J=8.0,8.0 \mathrm{~Hz}), 7.97(1 \mathrm{H}, \mathrm{d}, J=8.0 \mathrm{~Hz}), 7.99(1 \mathrm{H}, \mathrm{d}, J=$ $8.0 \mathrm{~Hz}), 8.80(1 \mathrm{H}, \mathrm{s}) .{ }^{13} \mathrm{C} \mathrm{NMR}\left(126 \mathrm{MHz}, \mathrm{CDCl}_{3}\right) \delta_{\mathrm{C}} 13.9$, $22.8,24.1,32.1,115.0\left(\mathrm{~d}, J_{\mathrm{CF}}=30 \mathrm{~Hz}\right), 122.9\left(\mathrm{~d}, J_{\mathrm{CF}}=7 \mathrm{~Hz}\right)$, $125.6\left(\mathrm{~d}, J_{\mathrm{CF}}=2 \mathrm{~Hz}\right), 127.6\left(\mathrm{~d}, J_{\mathrm{CF}}=2 \mathrm{~Hz}\right), 128.4,130.7$, $138.4\left(\mathrm{~d}, J_{\mathrm{CF}}=6 \mathrm{~Hz}\right), 148.6\left(\mathrm{~d}, J_{\mathrm{CF}}=16 \mathrm{~Hz}\right), 159.1\left(\mathrm{~d}, J_{\mathrm{CF}}=\right.$ $100232 \mathrm{~Hz}) .{ }^{19} \mathrm{~F}$ NMR $\left(470 \mathrm{MHz}, \mathrm{CDCl}_{3}\right) \delta_{\mathrm{F}} 79.3$ (br s). IR (neat) 2960, 2930, 2870, 1620, 1590, 1440,1425, 1250, 1220, 750 $\mathrm{cm}^{-1}$. MS (EI, $\left.20 \mathrm{eV}\right) \mathrm{m} / \mathrm{z} 203\left(\mathrm{M}^{+}, 67 \%\right), 160$ (100). Anal. Found: C, 76.54; H, 6.95; N, 6.76. Calcd for $\mathrm{C}_{13} \mathrm{H}_{14} \mathrm{FN}$ : C, $76.82 ; \mathrm{H}, 6.94 ; \mathrm{N}, 6.89 \%$.

\section{5}

\section{4-(Butan-2-yl)-3-fluoroisoquinoline (6b)}

Compound $\mathbf{6 b}$ was prepared by the method described for $\mathbf{6 a}$ using butyllithium $(0.65 \mathrm{~mL}, 1.62 \mathrm{M}$ in hexane, $1.05 \mathrm{mmol})$, $\mathrm{CF}_{3} \mathrm{CH}_{2} \mathrm{OTs}$ (127 mg, $\left.0.50 \mathrm{mmol}\right)$, tri(butan-2-yl)butylborane $110(0.55 \mathrm{~mL}, 1.0 \mathrm{M}$ in THF, $0.55 \mathrm{mmol})$, HMPA $(0.63 \mathrm{~mL})$, triphenylphosphine $\quad(11 \quad \mathrm{mg}, \quad 0.040 \quad \mathrm{mmol})$, tris(dibenzylideneacetone)dipalladium-chloroform (1/1) (10 $\mathrm{mg}, 0.010 \mathrm{mmol}), o$-iodobenzaldehyde $(104 \mathrm{mg}, 0.45 \mathrm{mmol})$ and copper(I) iodide $(95 \mathrm{mg}, 0.50 \mathrm{mmol})$ in THF $(2.5 \mathrm{~mL})$. 115 Then, crude aldehyde $\mathbf{3 b}$ was treated with $\mathrm{NH}_{4} \mathrm{OAc}(173 \mathrm{mg}$, $2.2 \mathrm{mmol})$ and $\mathrm{H}_{2} \mathrm{O}(0.22 \mathrm{~mL}, 1.8 \mathrm{mmol})$ in DMF $(4.5 \mathrm{~mL})$. 
Purification by thin layer chromatography on silica gel (AcOEt-hexane 1:10, and then benzene-AcOEt-hexane $1: 10: 10)$ to give $6 \mathbf{b}(65 \mathrm{mg}, 71 \%) .{ }^{1} \mathrm{H}$ NMR $(500 \mathrm{MHz}$, $\left.\mathrm{CDCl}_{3}\right) \delta_{\mathrm{H}} 0.86(3 \mathrm{H}, \mathrm{t}, J=7.3 \mathrm{~Hz}), 1.46(3 \mathrm{H}, \mathrm{dd}, J=7.3 \mathrm{~Hz}$, $\left.J_{\mathrm{HF}}=1.5 \mathrm{~Hz}\right), 1.82-2.14(2 \mathrm{H}, \mathrm{m}), 3.49(1 \mathrm{H}, \mathrm{tq}, J=7.3,7.3$ $\mathrm{Hz}), 7.52(1 \mathrm{H}, \mathrm{dd}, J=7.9,7.9 \mathrm{~Hz}), 7.70(1 \mathrm{H}, \mathrm{dd}, J=7.9,7.9$ $\mathrm{Hz}), 7.98(1 \mathrm{H}, \mathrm{d}, J=7.9 \mathrm{~Hz}), 8.14(1 \mathrm{H}, \mathrm{d}, J=7.9 \mathrm{~Hz}), 8.81$ $(1 \mathrm{H}, \mathrm{s}) .{ }^{13} \mathrm{C}$ NMR $\left(126 \mathrm{MHz}, \mathrm{CDCl}_{3}\right) \delta_{\mathrm{C}} 12.8,19.3\left(\mathrm{~d}, J_{\mathrm{CF}}=3\right.$ $\mathrm{Hz}), 28.5\left(\mathrm{~d}, J_{\mathrm{CF}}=3 \mathrm{~Hz}\right), 33.0\left(\mathrm{~d}, J_{\mathrm{CF}}=4 \mathrm{~Hz}\right), 119.1\left(\mathrm{~d}, J_{\mathrm{CF}}=\right.$ $1026 \mathrm{~Hz}), 123.1\left(\mathrm{~d}, J_{\mathrm{CF}}=6 \mathrm{~Hz}\right), 125.5\left(\mathrm{~d}, J_{\mathrm{CF}}=2 \mathrm{~Hz}\right), 127.6(\mathrm{~d}$, $\left.J_{\mathrm{CF}}=2 \mathrm{~Hz}\right), 128.5,130.6,138.5\left(\mathrm{~d}, J_{\mathrm{CF}}=7 \mathrm{~Hz}\right), 148.8\left(\mathrm{~d}, J_{\mathrm{CF}}\right.$ $=17 \mathrm{~Hz}), 159.3\left(\mathrm{~d}, J_{\mathrm{CF}}=235 \mathrm{~Hz}\right) \cdot{ }^{19} \mathrm{~F} \mathrm{NMR}(470 \mathrm{MHz}$, $\left.\mathrm{CDCl}_{3}\right) \delta_{\mathrm{F}} 86.1$ (br s). IR (neat) 2964, 2873, 1623, 1585, 1567, $1500,1442,1423,1380,1268,1247,1153,933,752 \mathrm{~cm}^{-1}$. MS 15 (EI, $70 \mathrm{eV}) \mathrm{m} / \mathrm{z} 203\left(\mathrm{M}^{+}, 37 \%\right), 174$ (100), 154 (17), 149 (14). Anal. Found: C, 76.58; H, 7.00; N, 6.80. Calcd for $\mathrm{C}_{13} \mathrm{H}_{14} \mathrm{FN}$ : C, 76.82; H, 6.94; N, 6.89\%.

\section{Reactions of 3-fluoroisoquinoline N-oxides}

\section{3-tert-Butoxy-4-butylisoquinoline $\boldsymbol{N}$-oxide (7a)}

To a solution of potassium tert-butoxide ( $63 \mathrm{mg}, 0.56 \mathrm{mmol})$ in THF $(2.5 \mathrm{~mL})$ was added a solution of $5 \mathbf{a}(82 \mathrm{mg}, 0.37$ $\mathrm{mmol})$ in THF $(2.0 \mathrm{~mL})$ at $-78{ }^{\circ} \mathrm{C}$. After the mixture was stirred for $30 \mathrm{~min}$ at $-78{ }^{\circ} \mathrm{C}$, the reaction was quenched with ${ }_{25} \mathrm{H}_{2} \mathrm{O}$-THF. Organic materials were extracted with AcOEt three times. The combined extracts were washed with brine and dried over $\mathrm{Na}_{2} \mathrm{SO}_{4}$. After removal of the solvent under reduced pressure, the residue was purified by thin layer chromatography on silica gel $(\mathrm{MeOH}-\mathrm{AcOEt} 1: 20)$ to give 7a $30(74 \mathrm{mg}, 72 \%)$ as colorless crystals. ${ }^{1} \mathrm{H}$ NMR $(500 \mathrm{MHz}$, $\left.\mathrm{CDCl}_{3}\right) \delta_{\mathrm{H}} 0.99(3 \mathrm{H}, \mathrm{t}, J=7.5 \mathrm{~Hz}), 1.49(2 \mathrm{H}, \mathrm{tq}, J=7.5,7.5$ $\mathrm{Hz}), 1.62(9 \mathrm{H}, \mathrm{s}), 1.61-1.68(2 \mathrm{H}, \mathrm{m}), 3.07(2 \mathrm{H}, \mathrm{t}, J=7.5 \mathrm{~Hz})$, $7.47(1 \mathrm{H}, \mathrm{dd}, J=7.8,7.8 \mathrm{~Hz}), 7.54(1 \mathrm{H}, \mathrm{ddd}, J=7.8,7.8,1.2$ $\mathrm{Hz}), 7.64(1 \mathrm{H}, \mathrm{d}, J=7.8 \mathrm{~Hz}), 7.82(1 \mathrm{H}, \mathrm{d}, J=7.8 \mathrm{~Hz}), 8.67$ ${ }_{35}(1 \mathrm{H}, \mathrm{s}) .{ }^{13} \mathrm{C} \mathrm{NMR}\left(126 \mathrm{MHz}, \mathrm{CDCl}_{3}\right) \delta_{\mathrm{C}} 13.9,23.0,26.6,29.1$, $31.9,87.2,123.5,125.1,126.1,127.2,127.4,128.2,129.6$, 135.0, 152.1. IR (KBr disk) 2960, 2920, 1590, 1465, 1360, 1320, 1230, 1180, 1150, $750 \mathrm{~cm}^{-1}$. MS (EI, $\left.20 \mathrm{eV}\right) \mathrm{m} / z 273$ $\left(\mathrm{M}^{+}, 2 \%\right), 217$ (100), 201 (15), 158 (12). HRMS $\mathrm{m} / \mathrm{z}$ calcd for ${ }_{40} \mathrm{C}_{17} \mathrm{H}_{23} \mathrm{NO}_{2} 273.1729\left(\mathrm{M}^{+}\right)$; found 273.1752.

\section{4-Butyl-3-phenylthioisoquinoline $\mathrm{N}$-oxide (7b)}

To a solution of thiophenol $(54 \mathrm{~mL}, 0.53 \mathrm{mmol})$ in THF $(1.0$ $\mathrm{mL})$ was added butyllithium $(0.35 \mathrm{~mL}, 1.51 \mathrm{M}$ in hexane, 0.53 $45 \mathrm{mmol})$ at $-78^{\circ} \mathrm{C}$. The reaction mixture was stirred for $30 \mathrm{~min}$ at $-78{ }^{\circ} \mathrm{C}$, and then a solution of $5 \mathrm{a}(96 \mathrm{mg}, 0.44 \mathrm{mmol})$ in THF $(2.0 \mathrm{~mL})$ was added at $-78^{\circ} \mathrm{C}$. After being stirred for $3 \mathrm{~h}$, the mixture was allowed to warm up to $0{ }^{\circ} \mathrm{C}$ and stirred for an additional $2 \mathrm{~h}$. The reaction was quenched with phosphate ${ }_{50}$ buffer ( $\left.\mathrm{pH} 7\right)$. Organic materials were extracted with $\mathrm{MeOH}-$ AcOEt $(1: 20)$ three times. The combined extracts were washed with brine and dried over $\mathrm{Na}_{2} \mathrm{SO}_{4}$. After removal of the solvent under reduced pressure, the residue was purified by thin layer chromatography on silica gel $(\mathrm{MeOH}-\mathrm{AcOEt}$ $\left.{ }_{55} 1: 20\right)$ to give $\mathbf{7 b}(115 \mathrm{mg}, 85 \%)$ as colorless crystals. ${ }^{1} \mathrm{H}$ NMR $\left(500 \mathrm{MHz}, \mathrm{CDCl}_{3}\right) \delta_{\mathrm{H}} 0.97(3 \mathrm{H}, \mathrm{t}, J=7.6 \mathrm{~Hz}), 1.51(2 \mathrm{H}, \mathrm{tq}, J$ $=7.6,7.6 \mathrm{~Hz}), 1.63(2 \mathrm{H}, \mathrm{tt}, J=7.6,7.6 \mathrm{~Hz}), 3.43(2 \mathrm{H}, \mathrm{t}, J=$ $7.6 \mathrm{~Hz}), 7.14-7.19(1 \mathrm{H}, \mathrm{m}), 7.21-7.24(4 \mathrm{H}, \mathrm{m}), 7.58-7.63$
(2H, m), 7.67-7.70 (1H, m), 7.93-7.96 (1H, m), $8.81(1 \mathrm{H}, \mathrm{s})$. ${ }_{60}{ }^{13} \mathrm{C}$ NMR $\left(126 \mathrm{MHz}, \mathrm{CDCl}_{3}\right) \delta_{\mathrm{C}} 13.8,23.0,31.4,32.8,124.5$, $125.3,126.5,127.8,127.9,128.8,129.1,129.4,129.6,134.5$, 135.0, 141.8, 144.1. IR (KBr disk) 3050, 2950, 2920, 1580, $1565,1480,1320,1185,1135,740 \mathrm{~cm}^{-1}$. MS (EI, $\left.70 \mathrm{eV}\right) \mathrm{m} / z$ $309\left(\mathrm{M}^{+}, 9 \%\right), 292$ (100), 250 (75), 174 (75), 115 (22), 77 65 (12). HRMS $m / z$ calcd for $\mathrm{C}_{19} \mathrm{H}_{19} \mathrm{NOS} 309.1187\left(\mathrm{M}^{+}\right)$; found 309.1216 .

\section{4-Butyl-3-(pyrrolidin-1-yl)isoquinoline $\mathbf{N}$-oxide (7c)}

To a solution of $\mathbf{5 a}(77 \mathrm{mg}, 0.35 \mathrm{mmol})$ in toluene $(2.0 \mathrm{~mL})$ 70 was added pyrrolidine $(0.12 \mathrm{~mL}, 1.4 \mathrm{mmol})$ at room temperature. After the reaction mixture was heated at reflux for $23 \mathrm{~h}$, volatile components were removed by evaporation under reduced pressure. The residue was purified by thin layer chromatography on silica gel $(\mathrm{MeOH}-\mathrm{AcOEt} 1: 20)$ to give 7c $75(69 \mathrm{mg}, 74 \%)$ as a pale brown solid. ${ }^{1} \mathrm{H}$ NMR $(500 \mathrm{MHz}$, $\left.\mathrm{CDCl}_{3}\right) \delta_{\mathrm{H}} 1.00(3 \mathrm{H}, \mathrm{t}, J=7.4 \mathrm{~Hz}), 1.50(2 \mathrm{H}, \mathrm{tq}, J=7.4,7.4$ $\mathrm{Hz}), 1.59-1.67(2 \mathrm{H}, \mathrm{m}), 2.06-2.10(4 \mathrm{H}, \mathrm{m}), 3.11-3.15(2 \mathrm{H}$, $\mathrm{m}), 3.35(4 \mathrm{H}, \mathrm{br} \mathrm{s}), 7.48-7.53(2 \mathrm{H}, \mathrm{m}), 7.64(1 \mathrm{H}, \mathrm{dd}, J=7.3$, $1.2 \mathrm{~Hz}), 7.86(1 \mathrm{H}, \mathrm{d}, J=8.5 \mathrm{~Hz}), 8.67(1 \mathrm{H}, \mathrm{s}) .{ }^{13} \mathrm{CNMR}(126$ $\left.{ }_{80} \mathrm{MHz}, \mathrm{CDCl}_{3}\right) \delta_{\mathrm{C}} 13.9,23.2,26.7,27.9,33.0,49.5,124.2$, $125.1,127.7,127.8,128.0,129.5,135.3,135.9,148.6$. IR (KBr disk) 3286, 2954, 2925, 1473, 1430, 1321, 1226, 1168 , $1122,759 \mathrm{~cm}^{-1}$. MS (EI, $\left.20 \mathrm{eV}\right) \mathrm{m} / z 270\left(\mathrm{M}^{+}, 12 \%\right), 254$ (100). HRMS $m / z$ calcd for $\mathrm{C}_{17} \mathrm{H}_{22} \mathrm{~N}_{2} \mathrm{O} 270.1732\left(\mathrm{M}^{+}\right)$; found 85270.1764 .

\section{4-Butyl-3-fluoro-1-anilinoisoquinoline (8a)}

To a solution of $\mathbf{5 a}(73 \mathrm{mg}, 0.32 \mathrm{mmol})$ in DMF $(4.0 \mathrm{~mL})$ was added phenyl isocyanate $(0.074 \mathrm{~mL}, 0.68 \mathrm{mmol})$. After the 90 reaction mixture was stirred at $100{ }^{\circ} \mathrm{C}$ for $21 \mathrm{~h}$, phosphate buffer ( $\mathrm{pH} \mathrm{7)}$ was added. Organic materials were extracted with AcOEt three times. The combined extracts were washed with brine and dried over $\mathrm{Na}_{2} \mathrm{SO}_{4}$. After removal of the solvent under reduced pressure, the residue was purified by 95 thin layer chromatography on silica gel (AcOEt-hexane 1:3) to give 8 a $(55 \mathrm{mg}, 57 \%)$ as a pale yellow solid. ${ }^{1} \mathrm{H}$ NMR (500 $\left.\mathrm{MHz}, \mathrm{CDCl}_{3}\right) \delta_{\mathrm{H}} 0.95(3 \mathrm{H}, \mathrm{t}, J=7.5 \mathrm{~Hz}), 1.43(2 \mathrm{H}, \mathrm{tq}, J=7.5$, $7.5 \mathrm{~Hz}), 1.61(2 \mathrm{H}, \mathrm{tt}, J=7.5,7.5 \mathrm{~Hz}), 2.89(2 \mathrm{H}, \mathrm{t}, J=7.5 \mathrm{~Hz})$, $7.05(1 \mathrm{H}, \mathrm{tt}, J=7.5,1.1 \mathrm{~Hz}), 7.15(1 \mathrm{H}$, br s) $7.34(2 \mathrm{H}, \mathrm{dd}, J$ $\left.{ }_{100}=8.6,7.5 \mathrm{~Hz}\right), 7.42(1 \mathrm{H}, \mathrm{dd}, J=7.8,7.8 \mathrm{~Hz}), 7.64(1 \mathrm{H}, \mathrm{dd}, J$ $=7.8,7.8 \mathrm{~Hz}), 7.68(2 \mathrm{H}, \mathrm{dd}, J=8.6,1.1 \mathrm{~Hz}), 7.88(1 \mathrm{H}, \mathrm{d}, J=$ $7.8 \mathrm{~Hz}), 7.89(1 \mathrm{H}, \mathrm{d}, J=7.8 \mathrm{~Hz}) .{ }^{13} \mathrm{C} \mathrm{NMR}(126 \mathrm{MHz}$, $\left.\mathrm{CDCl}_{3}\right) \delta_{\mathrm{C}} 14.0,22.6,23.6,32.2,104.4\left(\mathrm{~d}, J_{\mathrm{CF}}=31 \mathrm{~Hz}\right)$, $117.0\left(\mathrm{~d}, J_{\mathrm{CF}}=2 \mathrm{~Hz}\right), 120.0,122.0,122.9,123.9\left(\mathrm{~d}, J_{\mathrm{CF}}=7\right.$ $\left.{ }_{105} \mathrm{~Hz}\right), 124.5\left(\mathrm{~d}, J_{\mathrm{CF}}=2 \mathrm{~Hz}\right), 129.0,130.3,139.7\left(\mathrm{~d}, J_{\mathrm{CF}}=7 \mathrm{~Hz}\right)$, 139.7, $149.8\left(\mathrm{~d}, J_{\mathrm{CF}}=20 \mathrm{~Hz}\right), 157.2\left(\mathrm{~d}, J_{\mathrm{CF}}=20 \mathrm{~Hz}\right) \cdot{ }^{19} \mathrm{~F}$ NMR $\left(470 \mathrm{MHz}, \mathrm{CDCl}_{3}\right) \delta_{\mathrm{F}} 79.4$ (br s). IR (neat) 3450, 2950, $2870,1620,1540,1440,1415,1340,1120,755 \mathrm{~cm}^{-1}$. MS (EI, $70 \mathrm{eV}) \mathrm{m} / z 294\left(\mathrm{M}^{+}, 45 \%\right), 251$ (100), 204 (7), 128 (7), 77 110 (19). Anal. Found: C, 77.22; H, 6.64; N, 9.31. Calcd for $\mathrm{C}_{19} \mathrm{H}_{19} \mathrm{FN}_{2}$ : C, 77.52; H, 6.51; N, 9.52\%.

\section{Synthesis of 3-fluorocinnolines}

o-(1,1-Difluorohex-1-en-2-yl)aniline (9a)

115 Butyllithium (1.56 mL, 1.63 $\mathrm{M}$ in hexane, $2.5 \mathrm{mmol}$ ) was added to a solution of $\mathrm{CF}_{3} \mathrm{CH}_{2} \mathrm{OTs}(308 \mathrm{mg}, 1.21 \mathrm{mmol})$ in 
THF $(10 \mathrm{~mL})$ at $-78{ }^{\circ} \mathrm{C}$ over $10 \mathrm{~min}$. The reaction mixture was stirred for $20 \mathrm{~min}$ at $-78^{\circ} \mathrm{C}$, and then tributylborane $(1.33$ $\mathrm{mL}, 1.0 \mathrm{M}$ in THF, $1.33 \mathrm{mmol}$ ) was added at $-78{ }^{\circ} \mathrm{C}$. After being stirred for $1 \mathrm{~h}$, the reaction mixture was allowed to 5 warm up to room temperature and stirred for an additional $3 \mathrm{~h}$. The solution was treated with HMPA $(3.0 \mathrm{~mL})$, triphenylphosphine $\quad(25 \mathrm{mg}, \quad 0.10 \quad \mathrm{mmol})$ and tris(dibenzylideneacetone)dipalladium-chloroform (1/1) (25 $\mathrm{mg}, 0.024 \mathrm{mmol}$ ) and stirred for $15 \mathrm{~min}$. To the solution was 10 added the magnesium salt [generated from $o$-iodoaniline (238 $\mathrm{mg}, 1.09 \mathrm{mmol})$ and dibutylmagnesium $(2.47 \mathrm{~mL}, 0.44 \mathrm{M}$ in $\left.\mathrm{Et}_{2} \mathrm{O}, 1.09 \mathrm{mmol}\right)$ in THF $(3.0 \mathrm{~mL})$ at $0{ }^{\circ} \mathrm{C}$ ] and copper(I) iodide $(230 \mathrm{mg}, 1.21 \mathrm{mmol})$. After the mixture had been stirred for $1 \mathrm{~h}$ at room temperature, the reaction was quenched 15 with phosphate buffer $(\mathrm{pH} 7)$. The mixture was filtered throuth a Celite pad, and then organic materials were extracted with AcOEt three times. The combined extracts were washed with brine and dried over $\mathrm{Na}_{2} \mathrm{SO}_{4}$. After removal of the solvent under reduced pressure, the residue 20 was purified by column chromatography on silica gel (AcOEt-hexane $1: 10)$ to give 9a $(176 \mathrm{mg}, 77 \%)$ as a yellow liquid. ${ }^{1} \mathrm{H} \mathrm{NMR}\left(500 \mathrm{MHz}, \mathrm{CDCl}_{3}\right) \delta_{\mathrm{H}} 0.87(3 \mathrm{H}, \mathrm{t}, J=7.1 \mathrm{~Hz})$ $1.30-1.35(4 \mathrm{H}, \mathrm{m}), 2.29\left(2 \mathrm{H}, \mathrm{tdd}, J=7.0 \mathrm{~Hz}, J_{\mathrm{HF}}=2.3,2.3\right.$ $\mathrm{Hz}), 3.66(2 \mathrm{H}, \mathrm{br} \mathrm{s}), 6.70-6.77(2 \mathrm{H}, \mathrm{m}), 7.00(1 \mathrm{H}, \mathrm{dd}, J=7.6$, $\left.{ }_{25} 1.5 \mathrm{~Hz}\right), 7.12(1 \mathrm{H}, \mathrm{ddd}, J=7.6,7.6,1.5 \mathrm{~Hz}) .{ }^{13} \mathrm{C}$ NMR $(126$ $\left.\mathrm{MHz}, \mathrm{CDCl}_{3}\right) \delta_{\mathrm{C}} 13.8,22.4,27.7,29.8\left(\mathrm{dd}, J_{\mathrm{CF}}=3,3 \mathrm{~Hz}\right)$, $89.1\left(\mathrm{dd}, J_{\mathrm{CF}}=22,17 \mathrm{~Hz}\right), 115.6,118.4,119.0\left(\mathrm{~d}, J_{\mathrm{CF}}=3 \mathrm{~Hz}\right)$, 128.9, 130.6, (d, $\left.J_{\mathrm{CF}}=2 \mathrm{~Hz}\right), 144.3,152.8\left(\mathrm{dd}, J_{\mathrm{CF}}=290,288\right.$ $\mathrm{Hz}) .{ }^{19} \mathrm{~F} \mathrm{NMR}\left(470 \mathrm{MHz}, \mathrm{CDCl}_{3}\right) \delta_{\mathrm{F}} 68.7\left(1 \mathrm{~F}, \mathrm{~d}, J_{\mathrm{FF}}=43 \mathrm{~Hz}\right)$, $3072.7\left(1 \mathrm{~F}, \mathrm{~d}, J_{\mathrm{FF}}=43 \mathrm{~Hz}\right)$. IR (neat) 3475, 3375, 2960, 2930, 2860, 1740, 1620, 1495, $1230 \mathrm{~cm}^{-1}$. MS (EI, $\left.70 \mathrm{eV}\right) \mathrm{m} / z 211$ $\left(\mathrm{M}^{+}, 100 \%\right), 168$ (59), 148 (43). Anal. Found: C, 68.14; H, 7.07, N; 6.52. Calcd for $\mathrm{C}_{12} \mathrm{H}_{15} \mathrm{~F}_{2} \mathrm{~N}: \mathrm{C}, 68.23 ; \mathrm{H}, 7.16 ; \mathrm{N}$, $6.63 \%$.

35

$o$-(1,1-Difluoro-3-methylpent-1-en-2-yl)aniline (9b)

Compound $\mathbf{9 b}$ was prepared by the method described for $9 \mathbf{a}$ using butyllithium $(1.56 \mathrm{~mL}, 1.63 \mathrm{M}$ in hexane, $2.5 \mathrm{mmol})$, $\mathrm{CF}_{3} \mathrm{CH}_{2} \mathrm{OTs}$ (308 mg, $\left.1.21 \mathrm{mmol}\right)$, THF $(10 \mathrm{~mL})$, tri(butan-2$40 \mathrm{yl}$ )borane $(1.33 \mathrm{~mL}, 1.0 \mathrm{M}$ in THF, $1.33 \mathrm{mmol})$, HMPA $(3.0$ $\mathrm{mL})$, triphenylphosphine $(25 \mathrm{mg}, 0.10 \mathrm{mmol})$, tris(dibenzylideneacetone)dipalladium-chloroform (1/1) (25 $\mathrm{mg}, 0.024 \mathrm{mmol})$, $o$-iodoaniline $(238 \mathrm{mg}, 1.09 \mathrm{mmol})$, dibutylmagnesium (2.47 mL, $0.44 \mathrm{M}$ in $\left.\mathrm{Et}_{2} \mathrm{O}, 1.09 \mathrm{mmol}\right)$, 45 THF $(3.0 \mathrm{~mL})$ and copper(I) iodide $(230 \mathrm{mg}, 1.21 \mathrm{mmol})$. Purification by thin layer chromatography on silica gel (AcOEt-hexane 1:5) gave $\mathbf{9 b}(157 \mathrm{mg}, 68 \%)$ as a pale yellow liquid. ${ }^{1} \mathrm{H}$ NMR $\left(500 \mathrm{MHz},\left(\mathrm{CD}_{3}\right)_{2} \mathrm{SO}, 100{ }^{\circ} \mathrm{C}\right) \delta_{\mathrm{H}} 0.99(3 \mathrm{H}, \mathrm{t}$, $J=7.3 \mathrm{~Hz}), 1.03-1.15(3 \mathrm{H}, \mathrm{m}), 1.31-1.45(1 \mathrm{H}, \mathrm{m}), 1.54-1.66$ ${ }_{50}(1 \mathrm{H}, \mathrm{m}), 2.44-2.58(1 \mathrm{H}, \mathrm{m}), 4.58(2 \mathrm{H}, \mathrm{br} \mathrm{s}), 6.62(1 \mathrm{H}, \mathrm{ddd}, J$ $=7.4,7.4,1.4 \mathrm{~Hz}), 6.79(1 \mathrm{H}, \mathrm{d}, J=7.4 \mathrm{~Hz}), 6.92(1 \mathrm{H}, \mathrm{d}, J=$ $7.4 \mathrm{~Hz}), 7.07(1 \mathrm{H}$, ddd, $J=7.4,7.4,1.4 \mathrm{~Hz}) .{ }^{13} \mathrm{C}$ NMR $(126$ $\left.\mathrm{MHz},\left(\mathrm{CD}_{3}\right)_{2} \mathrm{SO}, 100{ }^{\circ} \mathrm{C}\right) \delta_{\mathrm{C}} 10.1,17.2,26.9,34.5,92.4(\mathrm{dd}$, $\left.J_{\mathrm{CF}}=16,16 \mathrm{~Hz}\right), 114.5,115.4,116.1,127.8,129.6,145.8$, ${ }_{55} 151.7\left(\mathrm{dd}, J_{\mathrm{CF}}=290,288 \mathrm{~Hz}\right) .{ }^{19} \mathrm{~F}$ NMR $\left(470 \mathrm{MHz},\left(\mathrm{CD}_{3}\right)_{2} \mathrm{SO}\right.$, $\left.100{ }^{\circ} \mathrm{C}\right) \delta_{\mathrm{F}} 71.2\left(1 \mathrm{~F}\right.$, br d, $\left.J_{\mathrm{FF}}=49 \mathrm{~Hz}\right), 74.1\left(1 \mathrm{~F}\right.$, br d, $J_{\mathrm{FF}}=$ $49 \mathrm{~Hz}$ ). IR (neat) 3390, 2960, 1730, 1615, 1495, 1455, 1300, 1215, 935, $750 \mathrm{~cm}^{-1}$. MS (EI, $\left.70 \mathrm{eV}\right) \mathrm{m} / z 211\left(\mathrm{M}^{+}, 100 \%\right)$,
182 (57), 162 (82). HRMS $m / z$ calcd for $\mathrm{C}_{12} \mathrm{H}_{15} \mathrm{~F}_{2} \mathrm{~N} 211.1173$ $60\left(\mathrm{M}^{+}\right)$; found 211.1184 .

\section{4-Butyl-3-fluorocinnoline (10a)}

To a solution of $9 \mathrm{a}(65 \mathrm{mg}, 0.31 \mathrm{mmol})$ in $\mathrm{CH}_{3} \mathrm{CN}(3.0 \mathrm{~mL})$ were added $\mathrm{CF}_{3} \mathrm{CO}_{2} \mathrm{H}(0.045 \mathrm{~mL}, 0.61 \mathrm{mmol})$ and $i$-AmONO ${ }_{65}(0.081 \mathrm{~mL}, 0.61 \mathrm{mmol})$ at $0{ }^{\circ} \mathrm{C}$, and the reaction mixture was stirred for $30 \mathrm{~min}$. The mixture was treated with thiophenol $(0.10 \mathrm{~mL}, 0.92 \mathrm{mmol})$ and then stirred for $30 \mathrm{~min}$ at $0{ }^{\circ} \mathrm{C}$. The reaction was quenched with phosphate buffer $(\mathrm{pH} 7)$, and organic materials were extracted with AcOEt three times. The 70 combined extracts were washed with brine and dried over $\mathrm{Na}_{2} \mathrm{SO}_{4}$. After removal of the solvent under reduced pressure, the residue was purified by thin layer chromatography on silica gel (AcOEt-hexane 1:5) to give 10a $(55 \mathrm{mg}, 88 \%)$ as a yellow liquid. ${ }^{1} \mathrm{H}$ NMR $\left(500 \mathrm{MHz}, \mathrm{CDCl}_{3}\right) \delta_{\mathrm{H}} 0.98(3 \mathrm{H}, \mathrm{t}, J=$ $757.6 \mathrm{~Hz}), 1.47(2 \mathrm{H}, \mathrm{tq}, J=7.6,7.6 \mathrm{~Hz}), 1.71(2 \mathrm{H}, \mathrm{tt}, J=7.6$, $7.6 \mathrm{~Hz}), 3.09(2 \mathrm{H}, \mathrm{t}, J=7.6 \mathrm{~Hz}), 7.76-7.80(2 \mathrm{H}, \mathrm{m}), 8.00$ $8.05(1 \mathrm{H}, \mathrm{m}), 8.48-8.52(1 \mathrm{H}, \mathrm{m}) .{ }^{13} \mathrm{C} \mathrm{NMR}(126 \mathrm{MHz}$, $\left.\mathrm{CDCl}_{3}\right) \delta_{\mathrm{C}} 13.8,22.8,23.7,31.7,122.0\left(\mathrm{~d}, J_{\mathrm{CF}}=25 \mathrm{~Hz}\right)$, $122.8\left(\mathrm{~d}, J_{\mathrm{CF}}=7 \mathrm{~Hz}\right), 129.2\left(\mathrm{~d}, J_{\mathrm{CF}}=2 \mathrm{~Hz}\right), 129.4\left(\mathrm{~d}, J_{\mathrm{CF}}=5\right.$ $\left.{ }_{80} \mathrm{~Hz}\right), 130.5,131.5,150.5\left(\mathrm{~d}, J_{\mathrm{CF}}=2 \mathrm{~Hz}\right), 162.4\left(\mathrm{~d}, J_{\mathrm{CF}}=236\right.$ $\mathrm{Hz}) .{ }^{19} \mathrm{~F} \mathrm{NMR}\left(470 \mathrm{MHz} \mathrm{CDCl}_{3}\right) \delta_{\mathrm{F}} 67.6$ (br s). IR (neat) 2960, 2870, 1620,1580, 1535, 1440, 1320, 1235, 1135, 1080, $965,760 \mathrm{~cm}^{-1}$. MS (EI, $\left.70 \mathrm{eV}\right) \mathrm{m} / z 204\left(\mathrm{M}^{+}, 100 \%\right), 162(43)$, 133 (47). Anal. Found: C, 70.32; H, 6.28; N, 13.34. Calcd for ${ }_{85} \mathrm{C}_{12} \mathrm{H}_{13} \mathrm{FN}_{2}$ : C, 70.57; H, 6.42; N, 13.72\%.

\section{4-(Butan-2-yl)-3-fluorocinnoline (10b)}

Compound 10b was prepared by the method described for 10a using $\mathrm{CH}_{3} \mathrm{CN}(3.0 \mathrm{~mL}), \mathrm{CF}_{3} \mathrm{CO}_{2} \mathrm{H}(0.053 \mathrm{~mL}, 0.72 \mathrm{mmol}), i$ 90 AmONO (0.10 mL, $0.72 \mathrm{mmol}), 9 \mathbf{b}(76 \mathrm{mg}, 0.36 \mathrm{mmol})$ and thiophenol $(0.11 \mathrm{~mL}, 1.1 \mathrm{mmol})$. Purification by thin layer chromatography on silica gel (AcOEt-hexane 1:5) gave 10b (64 mg, 87\%) as a yellow liquid. ${ }^{1} \mathrm{H}$ NMR $\left(500 \mathrm{MHz}, \mathrm{CDCl}_{3}\right)$ $\delta_{\mathrm{H}} 0.87(3 \mathrm{H}, \mathrm{t}, J=7.2 \mathrm{~Hz}), 1.49\left(3 \mathrm{H}, \mathrm{dd}, J=7.2 \mathrm{~Hz}, J_{\mathrm{HF}}=1.5\right.$ $\left.{ }_{95} \mathrm{~Hz}\right), 1.87-2.03(2 \mathrm{H}, \mathrm{m}), 3.57(1 \mathrm{H}, \mathrm{tq}, J=7.2,7.2 \mathrm{~Hz}), 7.75-$ $7.80(2 \mathrm{H}, \mathrm{m}), 8.14-8.20(1 \mathrm{H}, \mathrm{m}), 8.48-8.54(1 \mathrm{H}, \mathrm{m}) .{ }^{13} \mathrm{C}$ NMR $\left(126 \mathrm{MHz}, \mathrm{CDCl}_{3}\right) \delta_{\mathrm{C}} 12.7,18.9\left(\mathrm{~d}, J_{\mathrm{CF}}=3 \mathrm{~Hz}\right), 28.2(\mathrm{~d}$, $\left.J_{\mathrm{CF}}=4 \mathrm{~Hz}\right), 33.0\left(\mathrm{~d}, J_{\mathrm{CF}}=3 \mathrm{~Hz}\right), 122.9\left(\mathrm{~d}, J_{\mathrm{CF}}=6 \mathrm{~Hz}\right), 125.8$ $\left(\mathrm{d}, J_{\mathrm{CF}}=22 \mathrm{~Hz}\right), 129.1\left(\mathrm{~d}, J_{\mathrm{CF}}=2 \mathrm{~Hz}\right), 129.4\left(\mathrm{~d}, J_{\mathrm{CF}}=7 \mathrm{~Hz}\right)$, $100130.7,131.5,150.6,162.4\left(\mathrm{~d}, J_{\mathrm{CF}}=238 \mathrm{~Hz}\right) .{ }^{19} \mathrm{~F}$ NMR $(470$ $\mathrm{MHz} \mathrm{CDCl}_{3}$ ) $\delta_{\mathrm{F}} 74.1$ (br s). IR (neat) 2960, 2940, 2860, 1565, $1525,1435,1315,1235,1130,760 \mathrm{~cm}^{-1}$. MS (EI, $\left.20 \mathrm{eV}\right) \mathrm{m} / \mathrm{z}$ $204\left(\mathrm{M}^{+}, 100 \%\right), 146$ (34). Anal. Found: C, 70.32; H, 6.54; N, 13.50. Calcd for $\mathrm{C}_{12} \mathrm{H}_{13} \mathrm{FN}_{2}$ : C, 70.57; H, 6.42; N, $13.72 \%$. 105

The present work is dedicated to Professor Kenji Uneyama, the 2007 recipient of the ACS Award for Creative Work in Fluorine Chemistry.

\section{Acknowledgements}

We are grateful to Bayer CropScience K.K. for financial support. 


\section{Notes and references}

${ }^{a}$ Department of Chemistry, Graduate School of Pure and Applied Sciences, University of Tsukuba, Tsukuba, Ibaraki 305-8571, Japan. Fax: +8129853 4237; Tel: +81 29853 4237;

5E-mail:junji@chem.tsukuba.ac.jp

${ }^{b}$ Department of Chemistry, Graduate School of Science, The University of Tokyo, Hongo, Bunkyo-ku, Tokyo 113-0033, Japan.

${ }^{c}$ Department of Applied Chemistry, Kyushu Institute of Technology,

Sensui-cho, Tobata, Kitakyushu 804-8550, Japan.

† Classical Baltz-Schiemann (fluorodediazotization) and Halex (halogen exchange) approaches are still extensively used. See, ref. 7.

\$ The possibility of $6 \pi$-electrocyclization in the formation of $\mathbf{5}, \mathbf{6}$, and $\mathbf{1 0}$ cannot be ruled out.

15 Recently, a site-selective (C-1), direct arylation of isoquinoline $\mathrm{N}$ oxides has been reported.

1 For a review on isoquinolines, see: (a) K. W. Bentley, The Isoquinoline Alkaloids, Harwood Academic, Amsterdam, 1998. For a 20 review on isoquinoline $N$-oxides, see: (b) A. Albini and S. Pietra, ed., Heterocyclic N-oxides, CRC Press, Boca Raton, 1991.

2 For a review on cinnolines, see: W. Lewgowd and A. Stanczak, Arch. Pharm. (Weinheim, Ger.), 2007, 340, 65-80.

3 For isoquinoline synthesis, see: (a) M. lvarez and J. A. Joule, Science of Synthesis, 2004, 15, 661-838; (b) K. Kobayashi, K. Hayashi, K. Miyamoto, O. Morikawa and H. Konishi, Synthesis, 2006, 29342938 and references therein. For isoquinoline $N$-oxide synthesis, see: (c) T. Sakamoto, Y. Kondo, N. Miura, K. Hayashi and H. Yamanaka, Heterocycles, 1986, 24, 2311-2314.

304 For cinnoline synthesis, see: (a) N. Haider and W. Holzer, Science of Synthesis, 2004, 16, 251-313; (b) A. Slevin, T. Koolmeister and M. Scobie, Chem. Commun., 2007, 2506-2508; (c) N. A. Zolnikova, L. G. Fedenok and N. E. Polyakov, Org. Prep. Proced. Int., 2006, 38, 476-480; (d) D. B. Kimball, T. J. R. Weakley and M. M. Haley, J.

35 Org. Chem., 2002, 67, 6395-6405 and references therein. (e) C. Rüchardt and V. Hassmann, Liebigs Ann. Chem., 1980, 908-927.

5 For reviews, see: (a) M. J. Silvester, Adv. Heterocycl. Chem., 1994, 59, 1-38; (b) M. J. Silvester, Aldrichimica Acta, 1991, 24, 31-38; (c) R. E. Banks, B. E. Smart and J. C. Tatlow, ed., Organofluorine Chemistry, Principles and Commercial Applications, Plenum, New York, 1994; (d) P. Kirsch, Modern Fluoroorganic Chemistry: Synthesis, Reactivity, Applications, Wiley-VCH, Weinheim, 2004.

6 For cross-coupling of aryl fluorides, see: (a) T. J. Korn, M. A. Schade, S. Wirth and P. Knochel, Org. Lett., 2006, 8, 725-728. (b) T. Saeki,

45 Y. Takashima and K. Tamao, Synlett, 2005, 1771-1774 and references therein. (c) L. Ackermann, R. Born, J. H. Spatz and D. Meyer, Angew. Chem. Int. Ed., 2005, 44, 7216-7219. (d) F. Mongin, L. Mojovic, B. Guillamet, F. Trécourt and G. Quéguiner, J. Org. Chem. 2002, 67, 8991-8994. (e) T. Braun and R. N. Perutz, Chem. Commun. 2002, 2749-2757. For nucleophilic replacement of heteroaryl fluorides, see: (f) E. Arzel, P. Rocca, P. Grellier, M. Labaeïd, F. Frappier, F. Guéritte, C. Gaspard, F. Marsais, A. Godard and G. Quéguiner, J. Med. Chem., 2001, 44, 949-960.

7 M. Hudlicky, A. E. Pavlath, ed., Chemistry of Organic Fluorine Compounds II, American Chemical Society, Washington, DC, 1995.

8 For reports on the synthesis of 3-fluoroisoquinolines, see: (a) J. Ichikawa, K. Sakoda, H. Moriyama and Y. Wada, Synthesis, 2006, 1590-1598; (b) J. Ichikawa, Y. Wada, H. Miyazaki, T. Mori and H. Kuroki, Org. Lett., 2003, 5, 1455-1458; (c) V. G. Kolechkina, A. M. Maksimov, V. E. Platonov and O. I. Osina, Russ. Chem. Bull., 2001, 50, 322-323; (d) J. L. Neumeyer and K. K. Weinhardt, J. Med. Chem., 1970, 13, 613-616. For a report on the synthesis and reaction of 3-fluoroisoquinoline $\mathrm{N}$-oxides, see: (e) $\mathrm{M}$. Bellas and $\mathrm{H}$. Suschitzky, J. Chem. Soc., 1964, 4561-4564.

659 For reports on the synthesis of fluorocinnolines, see: (a) T. Miyamoto, and J. Matsumoto, Chem. Pharm. Bull., 1988, 36, 1321-1327; (b) R. D. Chambers, J. A. H. MacBride and W. K. R. Musgrave, J. Chem. Soc. Chem. Commun., 1970, 739-740; (c) R. N. Castle, K. Adachi and W. D. Guither, J. Heterocycl. Chem., 1965, 2, 459-462.

7010 J. Ichikawa, J. Fluorine Chem., 2000, 105, 257-263.
11 (a) L.-C. Champeau, D. R. Stuart and K. Fagnou, Aldrichimica Acta, 2007, 40, 35-41; (b) J.-P. Leclerc and K. Fagnou, Angew. Chem. Int. Ed., 2006, 45, 7781-7786.

12 J. Ichikawa, Y. Wada, M. Fujiwara and K. Sakoda, Synthesis, 2002, 1917-1936.

This journal is o The Royal Society of Chemistry [year] 